\title{
Reliability Assessment based on pseudo-life distribution missile degradation data analysis
}

\author{
XI Wen Jun ${ }^{1, a}$, WANG Wen Shuang ${ }^{1, b}$ \\ ${ }^{1}$ Naval Aeronautical And Astronautical University, ShanDong YanTai, China \\ alinn836001@sina.cn, b743122852@qq.com
}

Keywords: missiles; field data; life; reliability

\begin{abstract}
Through the rational use of test data on a regular basis to assess the missile storage reliability. This paper studies the detection of the type of missile components, missile components for storage summarizes the proposed four kinds of missile site testing data acquisition program, and analyze the advantages and disadvantages of each scheme; take degenerate pseudo-life distribution data analysis methods to the field test data perform numerical example to verify the correctness and availability solutions.
\end{abstract}

\section{Introduction}

After missile storage, maintenance, and its reliability is typically reduced. To ensure the missile to maintain high reliability and readiness of the troops in the storage process must use the missile testing. However, the general method of the missile testing is periodic testing ${ }^{[1-3]}$.

Determine the most economical and reasonable lifetime missile approach is to conduct a small sample accelerated life test, which stresses the use of accelerated life testing missiles, shorten test time.[4] Nikulin et al [5] analyzed the commonly used experimental model and accelerated degradation model. Although the small sample accelerated life test methods economic rationality, but it is not the best solution for the missile, the best solution is based on the actual usage of the storage of missiles, missile-site use test data to establish the life of degradation model site assessment.

\section{Missile components analysis}

A. Detection type of missile parts

For the practical needs of the reliability study will be divided into five categories ${ }^{[5]}$ :

(1) little effect on its long-term storage, high reliability components;

(2) regular testing usually find fault them for repair or replacement of parts, usually mounted on the bomb is generally not only be installed in wartime use;

(3) usually regular testing, but always found fault repair parts installed in the bomb;

(4) performance parameters of the trend of parts and the like;

(5) shorter storage life and easy to replace, in order to meet the storage reliability regular replacement of components.

B. Missile parts storage case

For actual missile storage, testing, maintenance, replacement of the situation, the above five categories into three kinds of missile parts storage case: Class 1 for reliability to meet the storage requirements do not need to detect and repair and replacement of parts; Class 2 is unnecessary regular testing, only need regular replacement parts, the replacement cycle $\tau$ is as $n$ times as detection period $\mathrm{T}$, determined by the level of actual reliability requirements and replacement funds, funds and reliability if conditions permit, you can take $T=\tau$; class 3 for regular maintenance detected fault without replacing parts.

As can be seen from the above analysis, for Class 1 high reliability components, may not need to detect; for Class 2 parts, select a suitable replacement cycle T replaced with new parts, you can always keep a high degree of reliability. In fact, the missile weapon system testing and maintenance 
as little time on the Class 3 components carefully to detect and repair, so not only can greatly reduce the detection time for each shorten preparation time, you can also maintain high reliability and weaponry availability, focused use of limited resources to achieve. This requires forces to scientific and rational use of field test data on missile life were assessed to detect and predict the next time to avoid the missile "test surplus" or "lack of detection" appears.

\section{Data Acquisition}

Currently the project is commonly used by life evaluation missile accelerated life test methods, failure time data acquisition missiles, and then to assess the reliability of the missile, the missile got life. However, this method can not use at the grassroots level, one grassroots no relevant experimental conditions, the second grassroots can not afford the costs of testing.

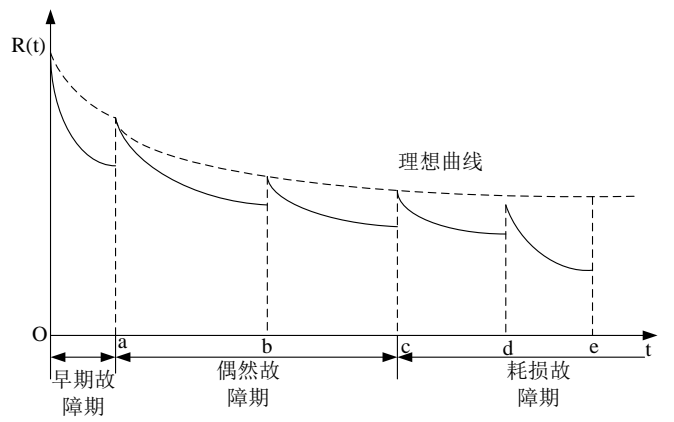

Fig.1 Effect of maintenance to reliability

In this regard, only the use of field test data to determine a reasonable life and missile detection time, be noted that the missile field test data, although slightly less accuracy. To sum up, the use of field test data on the life span of missiles. Reliability Assessment of degradation data distribution algorithm pseudo-life idea is related to the amount of degradation product performance parameters as a function of time or with (degenerate or degenerate trajectory model) using degenerate equation describes the relationship between the value of the pseudo-life stress level. Therefore, the data collection method is different from the data collection method based on failure data.

\section{A. The establishment of testing database}

Part of the test results can be accurately represented by the value, which is an accurate representation of numerical test results, according to the standard values and the acceptable range, determine eligibility components and establish the value of the test results with the standard contains a detector for each component of each missile The difference database A,additionally comprising a database established between two consecutive time intervals detected for each of the detection member B. Each missile Wherein A, B are $\mathrm{i} \times \mathrm{m} \times \mathrm{n}$ dimensional array.

Simple image of illustration, assume there are four missiles, from the armed forces has gone through nine testing, each test interval is not exactly the same (in units of h). Here take a component to establish a method to explain the database. Testing standards of the component is 97.300 (in V), the acceptable range for $[96,800,97,800]$, in accordance with the conversion requirements, establish a database as follows

$$
\begin{gathered}
\boldsymbol{A}=\left[\begin{array}{llllllllll}
0.025 & 0.131 & 0.246 & 0.357 & 0.561 & 0.011 & 0.116 & 0.247 & 0.476 \\
0.015 & 0.031 & 0.146 & 0.257 & 0.461 & 0.511 & 0.014 & 0.147 & 0.264 \\
0.125 & 0.281 & 0.406 & 0.597 & 0.161 & 0.311 & 0.436 & 0.544 & 0.112 \\
0.005 & 0.133 & 0.206 & 0.287 & 0.351 & 0.481 & 0.536 & 0.087 & 0.136
\end{array}\right] \\
\boldsymbol{B} \\
=\left[\begin{array}{lllllllll}
10 & 15 & 20 & 25 & 30 & 25 & 36 & 30 & 30 \\
10 & 15 & 20 & 25 & 30 & 25 & 36 & 30 & 30 \\
10 & 15 & 20 & 25 & 30 & 25 & 36 & 30 & 30 \\
10 & 15 & 20 & 25 & 30 & 25 & 36 & 30 & 30
\end{array}\right]
\end{gathered}
$$

After the completion of each test, the test results by the operator directly enter the established database, the test results will soon expand the array columns. 


\section{B. Data acquisition program}

According to the data analysis algorithm based on ideological degeneration pseudo life distribution for reasonable selection of samples, assuming a high efficiency plant maintenance, repair time is very short, the definition of "complete failure interval" for the first time to a failure of a component failure in this moment of time interval (defined as the failure to detect the 0th), associated with the test results and test data interval, get four kinds of data samples (four kinds of programs):

1) Select the i-th component of each missile last "complete failure zone" for the missiles to detect data samples of the i-th component;

2) Select all the "complete failure zone" for the missiles to the i-th component of the i-th sample test data for each component of the missile;

3) Select $n$ missiles i-th member of the last "complete fault section" i-th member of the detect data samples;

4) Select all the "complete failure zone" for the i-th component of the detected data sample $n$ i-th component of all missiles.

According to the database has been established, with the first three missiles i-th component detection database, for example, the last time the "complete failure zone" for the 4th detected eighth detection time interval, due to limited first three missiles, for example, Therefore, 2), 3), 4) the same results kinds of programs, the sample selection scheme 1) and Scheme 2), 3), 4) the results were:

$(0.161,30),(0.311,55),(0.436,91),(0.544,121)$, the sample size $\mathrm{N}=4$.

$(0.125,10),(0.28,25),(0.406,45),(0.597,70),(0.161,30),(0.311,55),(0.436,91),(0.544,121)$, the sample size $\mathrm{N}=8$.

\section{Statistical analysis}

Based on statistical analysis of degraded pseudo-life distribution before the traditional analysis of failure data adds different pseudo-failure data to determine the different data corresponding to the selected program specific data processing methods to Scheme 1), for example, specific steps include:

\section{A. Select Model}

Assuming a total of four missiles were detected nine times, for a part of the i-missile choice degenerate model is:

$$
y_{i j}=f\left(q_{i j}, \beta_{i}\right)+\varepsilon_{i j}
$$

\section{B. Extrapolation of data}

You can get the relevant parts of the missile test parameters specified threshold Y, life equation solver to use certain parts of the i given threshold missiles lifespan estimated by access to relevant information. Repeat the above steps to obtain all of the types of missile parts of failure data forecast estimate .

\section{Statistical Inference}

Analysis of the relationship between the structure and the various measurements specific missile components on this basis, the establishment of series, parallel, hybrid, next to the Union and other models to assess the reliability of the whole shells of missiles, missile whole shells get reliability. According to mission requirements, the need to ensure that the entire batch of missiles in $\mathrm{n}$ pieces maintain readiness, ready to hang can be used. Therefore, when assessing the reliability of the batch of missiles, the same system as the success or failure of n-type unit (each missile test results only qualified and two kinds of failures, all the detected fault is considered a part of any missile failure), with only when more than $\mathrm{k} I$ level unit testing of qualified, be considered to meet the requirements of system reliability, system as the upcoming voting system (k / n (G)). Assuming that the batch of missiles in the previous test, the pieces were detected $\mathrm{N}$ times, $\mathrm{S}$ gold determinations qualified, $\mathrm{F}$ gold determinations failure. The reliability of the system for maximum likelihood estimation:

$$
\hat{R}_{s}=\sum_{i=k}^{n}\left(\begin{array}{c}
n \\
i
\end{array}\right)\left(\frac{S}{N}\right)^{i}\left(\frac{F}{N}\right)^{n-i}
$$




\section{Calculate the example analysis}

In Scenario 1) The resulting simulation data as an example, the results shown in Figure 2-4. Figure 2 is the last time the "complete failure zone" and the last fault has been detected deviation versus time data. Figure 3 is the last time the "complete failure zone best-fit curve data.

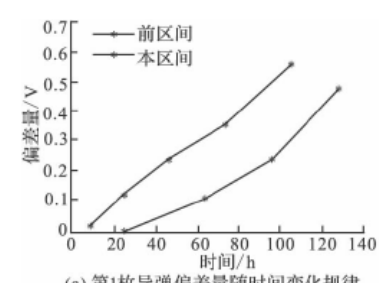

(a) 第1枚导弹偏差量随时间变化规律

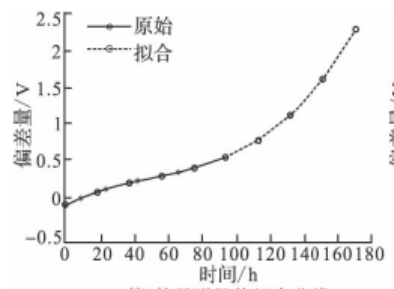

(a) 第1枚导弹最佳拟合曲线

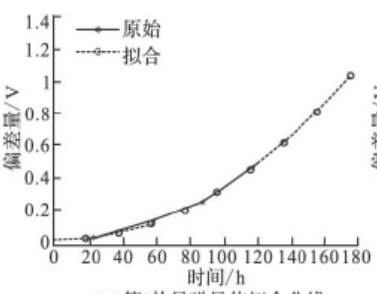

(a) 第1枚导弹最佳拟合曲线

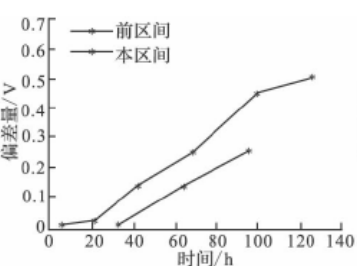

(b) 第2枚导弹偏差量随时间变化规律

Fig.2 Variation of deviation with time

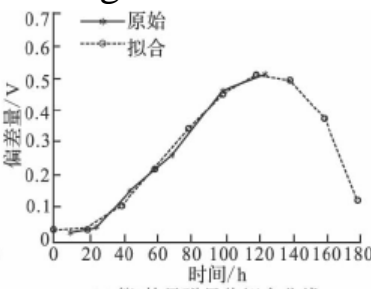

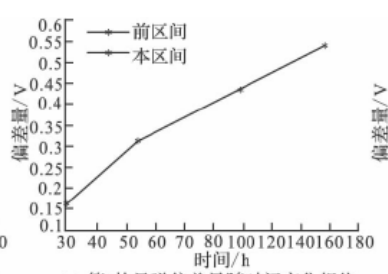

(c) 第3枚导弹偏差量随时间变化规律

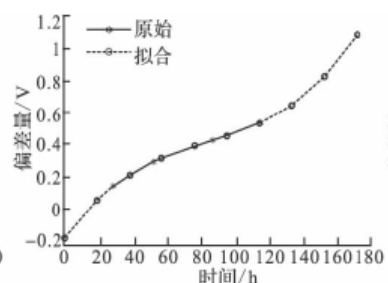

(c) 第3枚导弹最佳拟合曲线

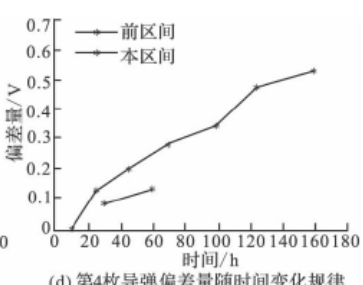

(d) 第4枚导弹偏差量随时间变化规律

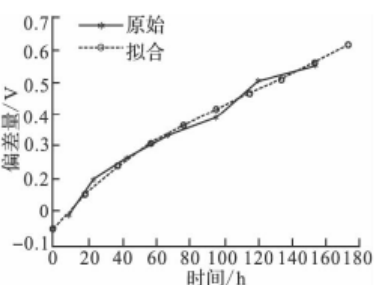

(d) 第4枚导弹最佳拟合曲线

Fig.3 Best stimulant curve

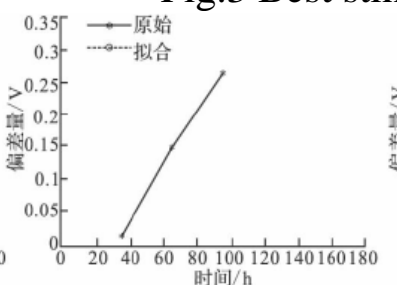

(b) 第2枚导弹最佳拟合曲线

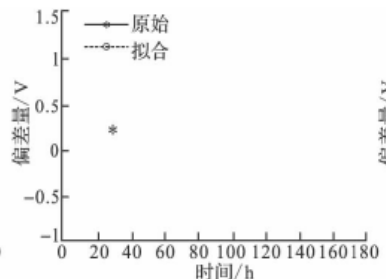

(c) 第3枚导弹最佳拟合曲线

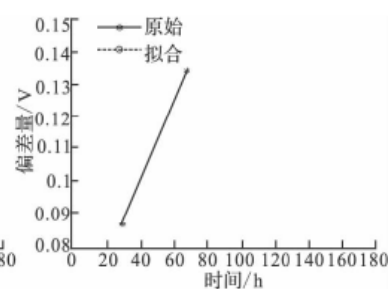

(d) 第4枚导弹最佳拟合曲线

Fig.4 Best stimulant curve

The last time the best-fit curve fault detection data so far. Figure 1 shows, the last time a missile "complete failure interval" The length of time for $100 \mathrm{~h}$, and after the last fault repair has $121 \mathrm{~h}$ still qualified, this case needs to be corrected predicted results from the original.

92.99h revised to $122.43 \mathrm{~h}$.Figure 4 shows that, due to the missile 2,3,4 last fault detection has insufficient data, the results can not be fitted, the result can only be used to predict the last "complete failure zone" of the data.

\section{Conclusion}

This paper studies the missile storage types, based on the analysis of the statistical analysis of the pseudo-life degradation data distribution method, presented four kinds of missile site testing data acquisition program, based on the reliability calculation step Scheme 1) is given, and a numerical example of missiles detection interval reasonable prediction, simulation results show the correctness of the proposed algorithm. Thus illustrate the use of the proposed scheme can effectively avoid the missile "test surplus" or "detect inadequate" and other issues, will help improve the availability of the missile during storage, and provides a reference for the storage and maintenance strategy actual missile .

\section{References}

[1] ZHU Bing-yu,ZHAN Xue-min,ZHANG Xing-you. Technology Overview of Foreign Missile[J]. Winged Missiles,2009(10):23-25.

[2] WANG Chun-hui,LI Zhong-dong,ZHANG Sheng-peng.Storage Life Analysis of Aircraft Missile[J]. Equipment Environmental Engineering,2011,8(4):68-72. 
[3] SUN Lin. Study of Quality Control of Product Process Based on Standard Deviation $\sigma$ prediction with WLS-SVM[J].Journal of Hefei University of Technology,2013,36(2):231-235.

[4] ZHANG Liang,ZHANG Xin-ping. Eliminating Intolerble Errors Contained in Flight Research Data[J]. Journal of Northwestern Polytechnical University,2011,29(4):637-639.

[5] CHEN Haijian,XU Tingxue,LI Bo,et al. Research on method of missile accelerated life test[J]. Equipment environmental engineering,2010,7(5):115-118.(in Chinese) 